\title{
Housing tiestall dairy cows in deep-bedded pens during an 8-week dry period: Effects on lying time, lying postures, and rising and lying-down behaviors
}

\author{
E. Shepley, ${ }^{1 *}$ G. Obinu, ${ }^{1,2}$ T. Bruneau,,${ }^{1,3}$ and E. Vasseur ${ }^{1}$ \\ ${ }^{1}$ Department of Animal Science, McGill University, Ste-Anne-de-Bellevue, QC H9X 3V9, Canada \\ ${ }^{2}$ Dipartimento di Agraria, Università degli Studi di Sassari, 017100 Sassari SS, Italy \\ ${ }^{3}$ Institut universitaire de technologie d’Angers-Cholet, Département Génie Biologique, Université d’Angers, 49300 Cholet, France
}

\section{ABSTRACT}

Dairy cow lying behavior is useful in determining the cow's level of welfare, as well as in determining how her environment may affect her comfort and ease of movement. In tiestall systems, cows usually remain in a stall for the duration of their lactation. The dry period offers a unique opportunity to provide alternative housing to the cow with minimal effects on farm housing and management. Our objective was to determine whether housing tiestall cows in deep-bedded pens over an 8-wk dry period altered lying time, lying and rising ability, or lying postures. At dry-off, 20 cows, paired by parity and calving date, were randomly assigned to a deep-bedded loose pen (LP) or a tiestall (TS). Leg-mounted pedometers measured lying time. Rising and lying ability were measured using 6 events of rising and lying from 24 -h video recordings taken once a week per cow. Sequenced images $(1 / \mathrm{min})$ from the 24-h recordings were used to document lying postures and locations for each cow. Data were analyzed for the early (first week of dry-off), mid, and late (week before calving) terms of the dry period. Lying time did not differ between LP and TS but was numerically higher for LP than TS cows (14.4 vs. $13.0 \mathrm{~h} / \mathrm{d}$, respectively). Contact with stall or pen confines when lying down was 5 times higher in TS than LP. The increased contact, coupled with a higher occurrence of hindquarter shifting in the late term, led to higher overall abnormal lying behaviors in TS. Contact with the stall upon rising increased in the late term for TS cows. Cows housed in loose pens also exhibited greater variation in hind-leg postures, keeping legs tucked $20 \%$ less often in favor of alternative postures. Stall hardware (e.g., tie rail, dividers) may have affected the ease of transition between lying and standing, leading to higher levels of

Received October 16, 2018.

Accepted March 5, 2019.

*Corresponding author: eshepley1@gmail.com contact with the stall. Loose-pen cows are able to assume more postures than TS cows when provided more space, possibly allowing them to orient themselves in ways that provide greater comfort. Lying surface in the deep-bedded loose pen may ease the cow's lying-down and rising movements and lead to the higher lying time found with LP cows. Overall, aspects of the stall largely contributed to differences in lying behaviors, warranting further study into whether freestall systems would yield similar outcomes. Improving our concept of ease of movement related to lying and quality of rest in dairy cows, through evaluating lying behaviors in different housing systems, allows for better recommendations on viable alternative housing options.

Key words: dry cow, ease of movement, housing, lying behavior

\section{INTRODUCTION}

Cows place a high value on access to lying (Cooper et al., 2007), with cows on commercial farms typically spending between 9 and $13 \mathrm{~h} / \mathrm{d}$ lying down (Ito et al., 2009). Indeed, cows exposed to just 2- and 4-h lying deprivation spent less time feeding once deprivation conditions were removed, to recover lost lying time (Cooper et al., 2007). Deviations from normal lying behaviors among individual cows have also been linked with several potential health issues, such as severe injury (Zambelis et al., 2018), lameness (Walker et al., 2008), and mastitis (Medrano-Galarza et al., 2012), as well as potential problems with the general comfort of the cow's lying surface (Tucker et al., 2009) or cubicle design (Fregonesi et al., 2009). For this reason, lying time has often been a key indicator of health and welfare status in dairy cattle research (Vasseur, 2017).

Several factors, from the moment the cow indicates her intentions to lie down to the time she rises again, may indicate the cow's level of comfort in her lying area and the ease with which she can lie down, change lying postures, and rise. The ability to transition be- 
tween lying and standing, for instance, has been found to correlate not only with physical welfare indicators, such as lameness or injury, but also with the size of the cow relative to her environment (Zambelis et al., 2018). More restrictive housing systems, such as those with standard-sized stalls, impede cows' rising and lying-down abilities compared with stalls doubled in width (Boyer et al., 2018) or with straw-yard housing systems that lack stall hardware entirely (Fregonesi et al., 2009). While the cow is lying, her posturing of her body, head, and limbs and use of her lying area may suggest her general level of comfort. Boyer et al. (2018) found that, when provided with a greater surface area for lying, cows adopted a greater variety of lying postures, particularly with regard to the posturing of the legs.

Although straw yards appear to be more advantageous to the expression of cow lying behaviors, most cows reside in housing systems that use cubicles, and tiestalls remain a prevalent housing system in the dairy industry, with over 74\% (CDIC, 2017) and 34\% (USDA, 2014) of cows in Canada and the United States, respectively, housed in tiestalls. The dry period offers a unique opportunity to provide alternative housing, with minimal effects on the existing housing system and onfarm management, for dairy cows normally housed in tiestalls during the course of lactation, as the cow no longer needs to be in the stall for daily milkings. The cow's environment can also have a significant effect on her overall welfare, especially during the dry period, as the dry cow undergoes several physiological changes and is managed differently than the lactating herd. The dry period is, therefore, an ideal time to investigate the effects of taking the cow out of the stall and to investigate different housing types that may better meet the needs of prepartum cows.

In the current study, we sought to determine whether housing tiestall dairy cows in a deep-bedded loose pen during an 8-wk dry period (1) increased the amount of time cows spent lying down and (2) improved ease of movement for cows when lying, through the ability to use different lying postures and when transitioning between lying and standing.

\section{MATERIALS AND METHODS}

\section{Ethics Statement}

A certified Animal Care Committee of McGill University and affiliated hospitals and research institutes reviewed and approved the use of animals in this project and all procedures (\#2016-7794). All aspects of this study meet the high standards established by the
Canadian Council on Animal Care to ensure the continued humane and ethical use of animals in research.

\section{Animals and Treatments}

This study was conducted at the Macdonald Campus Dairy Unit of McGill University (Sainte-Anne-deBellevue, Quebec, Canada). A total of 20 primiparous and multiparous Holstein cows were enrolled between August 2016 and March 2018 as they entered their dry period. Cows were blocked based on expected calving date and parity (mean $\pm \mathrm{SD}=2.1 \pm 1.00$ and 2.6 \pm 1.42 , range $=1-4$ and $1-6$, for tiestall and loose pen, respectively). Three cows were removed from the analysis for reasons unrelated to the treatment: one due to aborting her calf at the start of the dry period, one that was dried off prematurely, and a third due to poor temperament that hindered safe handling of the cow. This resulted in a total of 9 cows in the loose-pen treatment and 8 cows in the tiestall treatment used in the analysis. The cows in each of the paired groups were randomly allocated to 1 of the 2 treatment options: loose pen (LP) or tiestall (TS). Start dates for each pair were staggered over the course of the study from September 2016 to December 2017. Cows were dried off and enrolled 8 wk before their expected calving date; however, the mean amount of time between dry-off and calving for this study was 8.34 wk for TS (range: 7.29-9.86 wk) and 7.51 wk for LP (range: 6.57-8.71 wk). Cows in the LP treatment calved in their experimental pens. Cows in the TS treatment were moved to a calving pen when the barn staff observed physical signs of imminent calving (mean $3.63 \mathrm{~d}$ before calving, range 0-12 d). Physical signs included bagging up of the udder, mucosal discharge, swelling of the vulva, and changes in behaviors (e.g., restlessness, decreased appetite). After calving, both LP and TS cows were moved back to a tiestall housing system.

\section{Housing and Management}

Before enrollment in the study, all cows were housed in tiestalls. The deep-bedded loose-pen housing comprised 4 individual pens measuring $3.35 \times 4.88 \mathrm{~m}$ $\left(16.35 \mathrm{~m}^{2}\right.$ total $)$ each. Pens were bedded with straw to $20.0 \mathrm{~cm}$ in depth, with a base of concrete topped with $1.9 \mathrm{~cm}$-thick rubber mats (Animats, Animat Inc., Sherbrooke, QC, Canada). A thin layer of lime was applied to the rubber mats before bedding was placed. Each pen was fitted with a feed bin (Stack-N-Nest, LEWISBins+, Oconomowoc, WI) measuring $38.4 \mathrm{~cm}$ high $\times 76.5 \mathrm{~cm}$ wide $\times 60.96$ deep and a water bowl. The tiestall housing consisted of stalls measuring 1.41 
$\mathrm{m}$ wide $\times 1.87 \mathrm{~m}$ long. Stalls were bedded with $2.0 \mathrm{~cm}$ of wood shavings on a $4.4-\mathrm{cm}$ pasture mat base (KKM Longline, Distribution Multi-Mat, Inc., Ste-Cécile-deMilton, QC, Canada). A single water bowl was shared between every 2 stalls. Both the loose-pen and tiestall housing systems were designed to either meet or exceed current recommendations set by the Dairy Code of Practice (Dairy Farmers of Canada-National Farm Animal Care Council, 2009). Compressibility of the lying surface for both treatments was measured once during the trial using a 10-kg Clegg hammer (Clegg Impact Soil Tester, Lafayette Instrument Company, Lafayette, IN). The average compressibility of the tiestall base with $2 \mathrm{~cm}$ of bedding was $5.18 \mathrm{CIV} / \mathrm{H}$ (Clegg impact value/heavy hammer), and average compressibility of the deep-bedded loose pens was $4.85 \mathrm{CIV} / \mathrm{H}$. Lower values indicate higher compressibility.

Tiestalls were cleaned frequently, as per routine management, with any contaminants removed when seen by passing barn staff (avg. 15 passes/d). Fresh wood shavings were added daily to maintain $2 \mathrm{~cm}$ of bedding throughout the course of the study. Loose pens were cleaned once in the morning, with fresh bedding added to maintain a $20.0-\mathrm{cm}$ depth of bedding. Pens were also spot-cleaned once daily in the evening to remove any visible manure. All cows were fed 2 different rations during the course of the study: a far-off and a close-up TMR. An average of $21.1 \mathrm{~kg} / \mathrm{d}$ of far-off TMR was fed from the start of dry-off to 3 wk before expected calving and comprised $48.0 \%$ hay, $46.7 \%$ silage, $4.3 \%$ protein supplement, and $1.0 \%$ vitamin and mineral supplement. An average of $24.6 \mathrm{~kg} / \mathrm{d}$ of close-up TMR was fed from 3 wk before expected calving to the date of actual calving and comprised $17.2 \%$ hay, $69.0 \%$ silage, $9.0 \%$ protein supplement, $4.4 \%$ energy supplement, and $0.4 \%$ vitamin and mineral supplement. Rations were fed once in the morning at approximately $0700 \mathrm{~h}$. Hay was fed ad libitum to cows during the dry period.

\section{Measures}

Lying Time. Total lying time was recorded continuously throughout the dry period using a 3-dimensional pedometer (IceTag, IceRobotics, Edinburgh, UK) attached to a rear leg of the cow. Pedometer data were retrieved weekly. Data were output in 1-min intervals that were summed per day, and the sum of each day was then averaged by week. Lying times were analyzed for the early (first week of dry-off), mid, and late (last week before calving) terms of the dry period.

Lying-Down and Rising Behaviors. Cows in both treatment groups were observed via video recordings captured with overhead cameras (Smart Turret 2.8 for TS, Fisheye Camera for LP; Hikvision, Saint-
Laurent, QC, Canada). Recordings were taken once a week on the same day for each cow over the course of the study, and were used to measure behaviors related to lying down and rising, as well as lying postures. Cow lying-down and rising behaviors were measured using the methodology outlined by Zambelis et al. (2018), in which 6 separate events of lying and of rising, 4 during the day and 2 at night, were selected randomly from the total events captured over each 24 -h video recording period. From each of the 6 selected events, 8 lyingdown behaviors were recorded: intention movements before lying down, duration of lying motion, contact with the environment, attempts at lying, hindquarter shifting, dog sitting, lying on left or right side, and overall abnormal lying (Table 1). Similarly, 7 rising behaviors were recorded: total duration of rising event, contact with the environment, shuffling back on carpal joints, delayed rising, attempts at rising, horse rising, and overall abnormal rising (Table 2). All lying-down and rising behaviors are presented in the results as the average of the 6 selected events from each 24-h video recording. Binary classifications were reported as a percentage of the number of times (labeled as the \% occurrence) that the behaviors were recorded to have occurred across these 6 events.

Lying and rising behaviors were recorded for the early, mid, and late terms of the dry period. Observations of these behaviors were recorded by 3 observers, with interobserver reliability and intraobserver repeatability ranges recorded at (weighted kappa) $\mathrm{K}_{\mathrm{w}}=0.61-1.00$ and $\mathrm{K}_{\mathrm{w}}=0.88-1.00$, respectively, for lying-down behaviors. For interobserver reliability and intraobserver repeatability of rising behaviors, ranges were recorded at $\mathrm{K}_{\mathrm{w}}=0.64-1.00$ and $\mathrm{K}_{\mathrm{w}}=0.81-1.00$, respectively.

Lying Postures and Location. Based on the procedure outlined by Boyer et al. (2018), a multimedia framework video editing software (FFmpeg 4.0, 2000, https://ffmpeg.org/download.html\#release_4.0) was used to extract sequenced images of from each 24-h video recording, producing a single image per minute for use in 1-min instantaneous scan sampling of lying postures and locations of cows when lying (1,440 images/cow per week). Images in which the cows were lying down were reviewed by 2 trained observers. Lying postures are described in Table 3. Locations of the head and limbs were reported for cows housed in the TS treatment (Table 4; Figure 1). For cows in the LP treatment, pens were divided into 4 quadrants, with characteristics of each quadrant the same for each pen (Figure 2 ). Quadrant 1 was characterized by a shared divider with the adjoining pen and the water bowl, quadrant 2 shared an open divider with the adjoining pen and held no other resources, quadrant 3 had no adjoining pen and held the feed bin, and quadrant 4 also had no 
Table 1. Description of lying-down behaviors and sampling units, evaluated for tiestall (TS) and loose-pen (LP) treatments ${ }^{1}$

\begin{tabular}{|c|c|c|}
\hline Behavior & Sampling unit & Description \\
\hline $\begin{array}{l}\text { Duration of lying motion } \\
\text { (phase 2) }\end{array}$ & Seconds & $\begin{array}{l}\text { Length of time required to complete the lying motion } \\
\text { Start of motion: The cow descends to one of the forelegs } \\
\text { End of motion: The whole body touches the ground; body is stable }\end{array}$ \\
\hline Attempts at lying & Number of attempts & $\begin{array}{l}\text { The number of attempts required to successfully complete the lying motion } \\
\text { Failed lying attempt: Cow stands up after the start of a lying-down motion } \\
\text { (goes on one or both carpal joints and then back up onto hooves) }\end{array}$ \\
\hline Hindquarters shifting & Yes (1) or no (0) & $\begin{array}{l}\text { When on carpal joints, cow makes multiple shifting motions with its } \\
\text { hindquarters before lying down completely }(\geq 3 \mathrm{~s})\end{array}$ \\
\hline Lying on left or right & Left (1) or right (0) & $\begin{array}{l}\text { Direction the hind legs point when cow is lying (based on technician } \\
\text { viewing cow from above) }\end{array}$ \\
\hline Overall abnormal lying & Yes $(1)$ or no $(0)$ & $\begin{array}{l}\text { Cow requires }>1 \text { attempt to lie down or is scored as "Yes" for contact with } \\
\text { the environment, hindquarter shifting, or dog sitting }\end{array}$ \\
\hline
\end{tabular}

${ }^{1}$ Based on Zambelis et al. (2018).

${ }^{2}$ Adapted from Zambelis et al. (2018).

adjoining pen and was next to the pen entrance. A cow was recorded as being in a quadrant when more than $40 \%$ of her length was in that quadrant. As such, a cow could be recorded as being in more than one quadrant at the same time. Postures and locations were analyzed for the early, mid, and late terms of the dry period, and results were presented as a mean percentage of time each posture and location was recorded for all lying instances during a 24-h recording period. Interobserver reliability and intraobserver repeatability percent

Table 2. Description of rising behaviors and sampling units, evaluated for tiestall (TS) and loose-pen (LP) treatments $^{1}$

\begin{tabular}{|c|c|c|}
\hline Behavior & Sampling unit & Behavior \\
\hline Contact with environment ${ }^{2}$ & Yes $(1)$ or no $(0)$ & $\begin{array}{l}\text { While cow propels itself forward (with both carpal joints on the ground), its head or } \\
\text { neck touches the tie rail (TS) or pen wall (LP) }\end{array}$ \\
\hline Delayed rising & Yes $(1)$ or no $(0)$ & Cow rests on carpal joints for $>10 \mathrm{~s}$ \\
\hline Attempts at rising & $\begin{array}{l}\text { Number of } \\
\text { attempts }\end{array}$ & $\begin{array}{l}\text { The number of attempts required to successfully complete the rising motion } \\
\text { Failed lying attempt: Cow propels itself forward from the sternal position without } \\
\text { successfully rising; can appear as a forward-and-back motion }\end{array}$ \\
\hline
\end{tabular}

${ }^{1}$ Based on Zambelis et al. (2018).

${ }^{2}$ Adapted from Zambelis et al. (2018). 
Table 3. Ethogram with a description of observed postures, by body part, measured during lying for tiestall (TS) and loose-pen (LP) treatment cows $^{1}$

\begin{tabular}{|c|c|c|}
\hline Category & Posture & Description \\
\hline Body & $\begin{array}{l}\text { Lying on sternum } \\
\text { Lying on side }\end{array}$ & $\begin{array}{l}\text { The body is resting on the ground } \\
\text { The body is resting flat on one side, with the legs of the supported underside extended and the head } \\
\text { resting on the ground }\end{array}$ \\
\hline Head & $\begin{array}{l}\text { Upright } \\
\text { Back } \\
\text { Ground }\end{array}$ & $\begin{array}{l}\text { Cow is lying on the sternum, head raised off the ground } \\
\text { Cow is lying on the sternum, head positioned toward posterior of the cow, resting against the body } \\
\text { Cow is lying on the sternum or side, head stretched and resting on the floor }\end{array}$ \\
\hline Front leg & $\begin{array}{l}\text { Tucked } \\
\text { Extended }\end{array}$ & $\begin{array}{l}\text { Front leg is tucked under or to the side of the body (full plantar flexion at the humoral joint) } \\
\text { Front leg is extended in front of or to the side of the body }\end{array}$ \\
\hline Hind leg & $\begin{array}{l}\text { Tucked } \\
\text { Extended } \\
\text { Mid position }\end{array}$ & $\begin{array}{l}\text { Hind leg is positioned at an angle of fewer than } 45 \text { degrees in relation to the body axis or underneath } \\
\text { the body } \\
\text { Hind leg is positioned at an angle of } 90 \text { degrees or greater in relation to the body axis } \\
\text { Hind leg is positioned at an angle between } 45 \text { and } 90 \text { degrees in relation to the body axis }\end{array}$ \\
\hline
\end{tabular}

${ }^{1}$ Based on Haley et al. (2000).

agreement were recorded at $93.3 \%$ (range: $83.3-100 \%$ ) and $92.5 \%$ (range: $83.3-100 \%$ ), respectively.

\section{Statistical Analysis}

All analyses were run in a statistical analysis software, SAS 9.4 (2008; SAS Institute Inc., Cary, NC) and were conducted at the cow level using a mixed model procedure (PROC MIXED and LSMEANS), according to the following model:

$$
\begin{aligned}
\gamma_{\mathrm{ijkm}}=\mu & + \text { treatment }_{\mathrm{i}}+\text { block }_{\mathrm{ij}}+\text { cow }_{\mathrm{ijk}}+\text { term }_{\mathrm{m}} \\
& + \text { treatment }_{\mathrm{i}} \times \text { term }_{\mathrm{m}}+\mathrm{e}_{\mathrm{ijkm}},
\end{aligned}
$$

where $\gamma_{\mathrm{ijkm}}$ represents the observation, $\mu$ is the population mean, treatment $t_{i}$ is the fixed effect of the ith treatment (TS, LP), block $\mathrm{ij}_{\mathrm{ij}}$ is the fixed effect of the jth block in the ith treatment $(1-10), \operatorname{cow}_{\mathrm{ijk}}$ is the random effect of the kth cow in the jth block in the ith treatment $(1-2), t^{t e r m} m_{m}$ is the fixed effect of the mth term (early, mid, late), and $\mathrm{e}_{\mathrm{ijkm}}$ represents the residual error Repeated measures for term were analyzed using 2 relevant covariance structures: compound symmetry and autoregressive lag 1. Covariance structures, variance parameters, and coefficient of variance between TS and LP treatments for all measured variables can be found in Supplemental Table S1 (https://doi.org/10.3168/jds .2018-15859). Scheffé's adjustment was used to account for multiple comparisons in the analysis of term and the interaction between treatment and term. Normality was tested against the residuals for all variables using the PROC UNIVARIATE and PROC MIXED procedures. Horse rising and dog sitting were not observed to have occurred and thus could not be run by the analytical software and were excluded from analysis. The analyses for locations in which postures were recorded for both tiestall and loose-pen animals were run separately and

Table 4. Description of the observed locations of cow limbs and head in relation to the stall environment (Figure 1) for cows in tiestall treatment group when lying down

\begin{tabular}{lll}
\hline Body part & Location & Description \\
\hline Head & $\begin{array}{l}\text { Divider } \\
\text { Manger } \\
\text { Stall } \\
\text { Neighbor's stall }\end{array}$ & $\begin{array}{l}\text { The head is resting on the stall divider } \\
\text { Muzzle is encroaching on the manger area (beyond the stall-manger border) } \\
\text { Muzzle is behind the stall-manger border, within the borders of the stall bed } \\
\text { Muzzle is encroaching on the neighboring cow's stall (beyond the stall divider) }\end{array}$ \\
& $\begin{array}{l}\text { Manger } \\
\text { Front leg }\end{array}$ & $\begin{array}{l}\text { Front leg extends over the manger wall and into the manger area (beyond the stall-manger border) } \\
\text { Front leg is behind the stall-manger border, within the borders of the stall bed }\end{array}$ \\
& $\begin{array}{l}\text { Neighbor's stall } \\
\text { Front leg extends into the neighboring cow's stall (beyond the stall divider) }\end{array}$ \\
Hind leg & $\begin{array}{l}\text { Stall } \\
\text { Neighbor's stall }\end{array}$ & $\begin{array}{l}\text { Hind leg is positioned within the borders of the stall bed } \\
\text { Hind leg extends into the neighboring cow's stall (beyond the stall divider) }\end{array}$ \\
& Hind leg extends outside of the stall bed, encroaching on the alleyway (beyond the stall's curb)
\end{tabular}

\footnotetext{
${ }^{1}$ Adapted from Haley et al. (2000).
} 


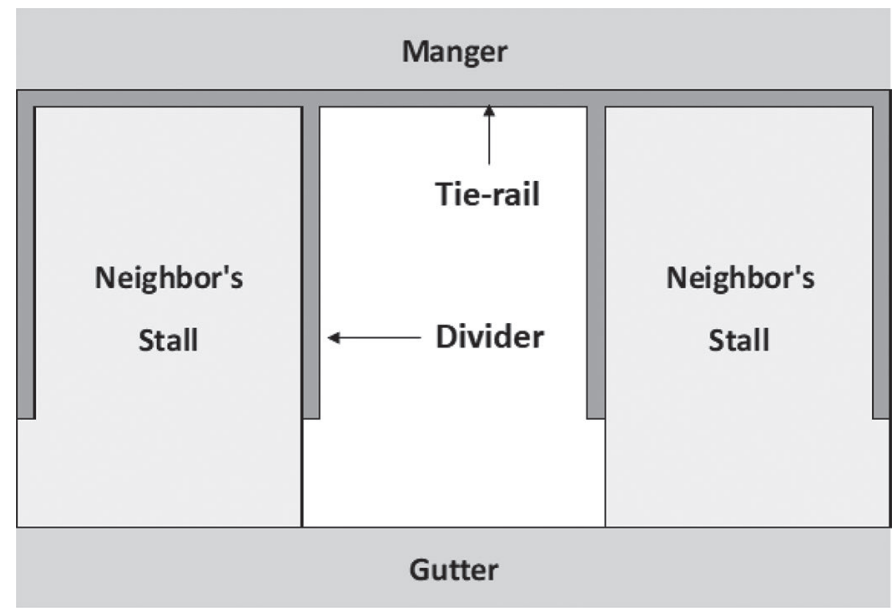

Figure 1. Locations in and around the stall environment used for observing the locations of the limbs and head for tiestall-housed treatment cows when lying down.

therefore did not have treatment as a fixed effect but otherwise followed the same statistical analysis process as the other variables.

\section{RESULTS}

\section{Lying Time}

There was no significant difference in lying time between TS and LP treatments $[12.97 \pm 0.63$ vs. $14.43 \pm$ $0.58 \mathrm{~h} / \mathrm{d}$, respectively; denominator degrees of freedom $($ ddf $)=5.95 ; F$-value $=2.22 ; P=0.15]$; see Supple- mental Tables S2 and S3 (https://doi.org/10.3168/jds $.2018-15859)$. There was an effect of term $(P<0.05)$, with lying time increasing over the course of the dry period for both TS and LP cows. However, once multiple comparisons were accounted for, only tendency was retained between lying time in the early and mid terms of the dry period $(+0.76$ and $+0.79 \mathrm{~h} / \mathrm{d}$ for TS and LP, respectively; $P=0.07)$.

\section{Lying-Down Ability}

The duration of the intention time before lying down was $5 \mathrm{~s}$ longer for LP cows than for TS cows (Table 5; $P<0.05$ ). Additionally, there was an effect of term on intention time, with both treatments requiring a higher duration of time to decide to lie down in the mid $(+1.16 \mathrm{~s}$ and $+3.56 \mathrm{~s}$ for TS and LP, respectively) and late term $(+7.09 \mathrm{~s}$ and $+10.67 \mathrm{~s})$ compared with the early term. Contact with the confines of the cow's housing environment when lying down was higher for TS cows than for LP $(P<0.01)$, with contact occurring more than 5 times more often in the tiestalls. The occurrence of hindquarter shifting was higher at the end of the dry period than during the beginning or mid term $(P<0.05)$, with a tendency for a higher occurrence of hindquarter shifting in TS cows in the late term compared with the mid term $(+27.08 \%, P<0.1)$. Overall abnormal lying was found to occur 3.8 times more often in TS cows than in their LP counterparts $(P<0.01)$, with the higher occurrence of hindquarter shifting and contact found in TS cows being the leading contributors to this significance.

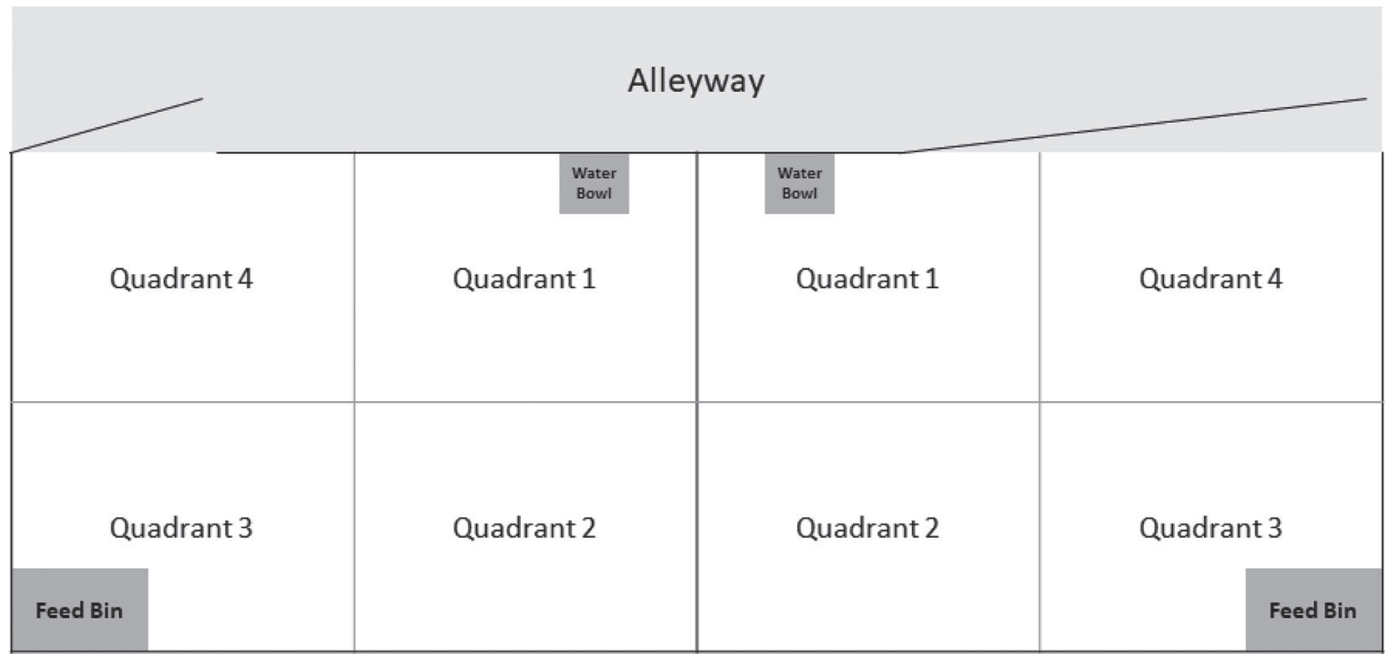

Figure 2. A depiction of the division of the loose-pen environment into 4 quadrants for use in recording the lying locations of loose-pen treatment cows when lying down. 
Table 5. Lying-down behaviors reflecting the ability of the cow to transition from standing to lying when housed in a tiestall (TS) or loose pen $(\mathrm{LP})$, presented as a treatment mean $\pm \mathrm{SE}$, averaged across the early, mid, and late term

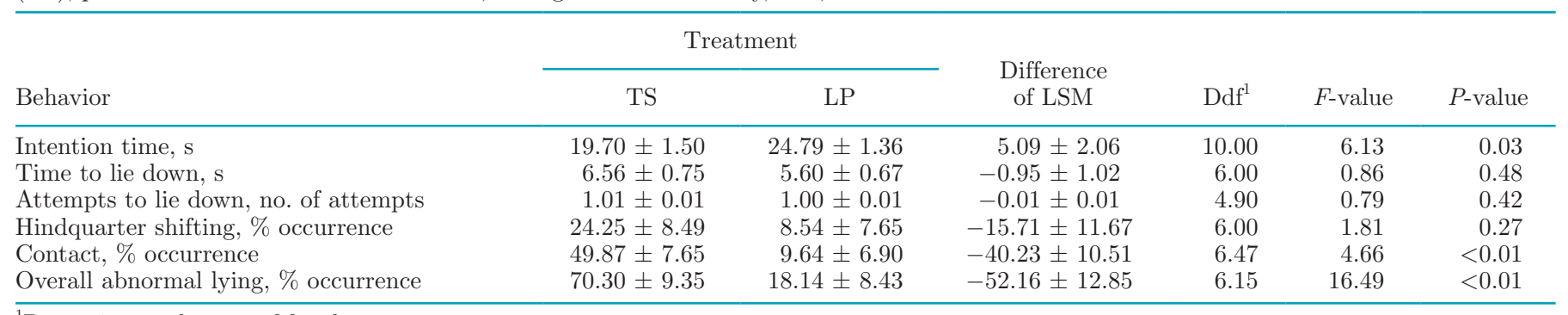

${ }^{1}$ Denominator degrees of freedom.

\section{Rising Ability}

There was no difference between treatments on any measured behaviors related to the cow's ability to rise (Table 6). Although not significant, time to rise was numerically longer for TS cows than for LP cows $(9.2$ s vs. $6.2 \mathrm{~s} ; P=0.12$ ). There was a treatment $\times$ term interaction for contact with the confines of the cow's housing environment when rising $(P<0.05)$, with the percentage of times when cows made contact increasing over $10 \%$ by the end of the dry period for TS cows and decreasing by over $6 \%$ for LP cows $(+10.41 \%$ vs. $-6.29 \%$ for change between early and late term for TS and LP, respectively).

\section{Lying Postures and Locations}

Cows housed in the LP treatment for the duration of the dry period apportioned their lying time more evenly between the 3 different hind-leg postures, with $20 \%$ less time spent with the hind legs tucked compared with TS cows $(69.77 \pm 1.92 \%$ vs. $89.29 \pm 2.14 \%$, respectively; $P<0.01$; Figure 3 ). In the LP group, cows also spent more time than TS cows with their hind legs in the mid position $(18.97 \pm 2.14 \%$ vs. $6.80 \pm 2.38 \%$; $P<0.01)$ and extended postures $(11.09 \pm 1.84 \%$ vs. $3.75 \pm 2.04 \% ; P<0.05)$. Cows in the LP group tended to position their heads upright less often than TS cows
$(91.25 \pm 0.39 \%$ vs. $92.51 \pm 0.43 \%$, respectively; $P=$ $0.05)$, instead spending more time resting their heads toward the back $(8.32 \pm 0.58 \%$ vs. $6.38 \pm 0.64 \% ; P=$ $0.07)$.

There was no significant difference between the time spent lying in any of the 4 quadrants in the LP treatment; however, cows spent numerically more time in quadrant 2 (46.0\% for quadrant 2 vs. $23.8-28.3 \%$ for quadrants 1,3 , and $4 ; P=0.16)$. In the TS treatment, use of different locations in and around the stall (e.g., gutter, stall, neighbor's stall) was not affected by term. In the mid and extended positions, TS cows' hind legs were found to be in a neighboring stall $65.54 \pm 7.01 \%$ (mean \pm S.E., range $=0-100 \%)$ and $79.26 \pm 5.12 \%$ (range $=0-100 \%$ ) of the time, respectively. When the front leg was in the extended position, it was observed to be in a neighbor's stall $16.11 \pm 5.20 \%$ of the time (range: $0-100 \%$ ).

\section{DISCUSSION}

Several factors relating to housing characteristics of the 2 treatment areas may have contributed to the differences in lying behaviors that the current study found. Particularly with regard to lying-down and rising ability, the presence of stall hardware appeared to have a considerable effect. Contact with the tie rail when rising increased for TS cows during the late dry period, sug-

Table 6. Rising behaviors reflecting the ability of the cow to transition from lying to standing when housed in a tiestall (TS) or loose pen (LP), presented as mean $\pm \mathrm{SE}$, averaged across the early, mid, and late term

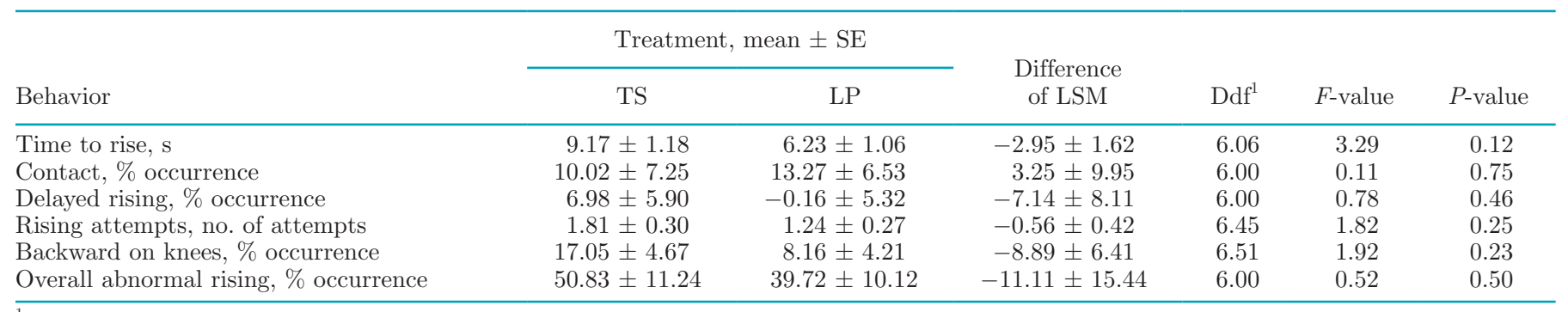

${ }^{1}$ Denominator degrees of freedom. 


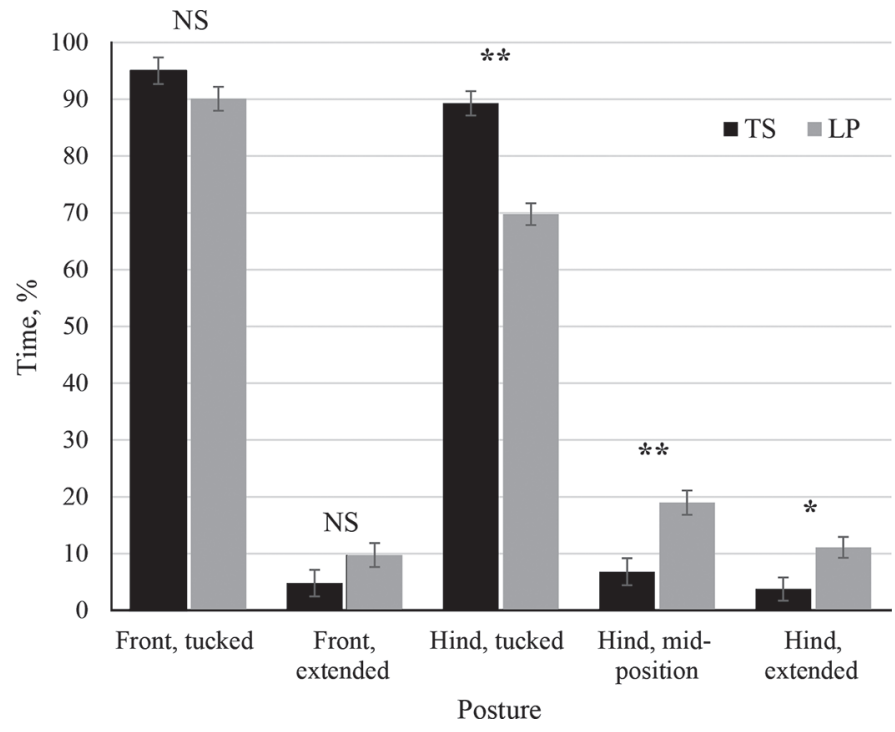

Figure 3. The percentage of time spent in a tucked, extended, or mid position for front- and hind-leg postures, presented as the mean value, for cows in tiestall (TS; black) and loose-pen (LP; gray) treatment groups. Error bars represent the SEM. Time spent differed between TS and LP treatments at ${ }^{*} P<0.05$ or ${ }^{*} P<0.01$.

gesting that these animals may experience a reduction in ease of movement when rising. The tie rail has been shown to be a point of contact for cows when rising and a possible explaining factor for welfare concerns such as neck injury in the cow (Bouffard et al., 2017). Cows housed in deep-bedded loose pens, conversely, showed a numeric decrease in contact over the course of the dry period, suggesting that cows adapt to their environment and learn to avoid contact in their environment, whereas tiestall cows have less opportunity to do so. St. John et al. (2018) attributed a $14.3 \%$ reduction in contact with the tiestall over a 10 -wk period for lactating cows to adaptation to their treatment stalls, with most of the reduction $(-11.1 \%)$ observed by the midpoint of the study. However, results for tiestall cows in the current study found the opposite, necessitating further research into stall hardware options for dry cows in tiestall housing (e.g., more flexible material to absorb part of the force applied during contact).

Perhaps more severe with regard to movement impeded by stall hardware was the level of contact with the stall dividers during the lying-down movement, with cows coming in contact with the confines of the stall around half of the time. Larger cows have been found to be more affected by stall confines, with a study by Zambelis et al. (2018) finding that larger cow widths were positively correlated with increases in contact with the stall confines when lying down. In similar studies, contact decreased over time by $6.3 \%$ (Boyer et al., 2018) and 21.6 to 50.6\% (St. John et al., 2018), compared with the $10 \%$ numeric increase seen in our study. Although the current study did not account for cow girth, cow size may have increased during the dry period from the beginning of the study as a result of progressing gestation. Hindquarter shifting may have been used by TS cows in the late term of the dry period; the tendency for TS cows use hindquarter shifting as a means to adjust their bodies to avoid collisions with environmental impediments nearly tripled over the course of the study. Increasing stall width is one method for improving ease of movement within the stall, particularly for larger cows and cows housed in tiestalls during the dry period. For instance, distancing the cow from stall dividers by doubling stall width can lead to similar reductions in contact with the cow's environment (-34\%; Boyer et al., 2018), improving overall ease of movement when lying down. Eliminating the stall altogether, as we did in the LP treatment of our current study, further reduced environmental collisions.

Cow preference for lying area within her environment is also a method for determining how environmental characteristics affect the cow. In our study, loose-pen cows showed no significant difference in lying location but did numerically use quadrant 2 most frequently. This is notable, as this quadrant was devoid of resources (i.e., water bowl, food bin, doorway) that may reduce available space in other quadrants and may disrupt the cow when transitioning between lying and standing. This may also be evident in the higher intention time in the LP cows' lying-down behavior compared with TS cows; this is contrary to previous studies on lactating cows, which show that more space results in a lower intention time (e.g., pasture vs. tiestall in Krohn and Munksgaard, 1993; double-width tiestall vs. normalwidth tiestall in Boyer et al., 2018). It is possible that the LP cows in our study were more discerning in their choice of lying area and, as a result, initiated longer intention movements before deciding where to lie down than TS cows, whose choices were limited.

Alluded to when discussing the presence or absence of stall hardware is another defining feature that differentiates the tiestall treatment area from that of the loose pen: space allowance. Space allowance may have influenced the variety of lying postures used by the cows, facilitating alternative resting postures in LP cows. For example, LP cows in the current study tended to position their heads toward their back in a full resting posture more than TS cows, concurring with previous studies in both loose-pen housing (5.3 vs. $4.8 \%$, loose pen vs. tiestall, respectively; Haley et al., $2000)$ and in cows housed in double-width stalls (8.1 vs. $7.2 \%$, double-width vs. standard-width stall, respectively; Boyer et al., 2018). Positioning the head to rest toward the back has been associated with rapid eye 
movement sleep in dairy cows (Ternman et al., 2014), signifying this position to be indicative of deep sleep in the animal.

Likewise, more space may have increased the ease with which cows moved between different leg postures, resulting in more displays of partial and full leg extension in LP cows. Offering stalls that were doubled in width from a standard-sized stall $(2.8 \mathrm{~m}$ vs. $1.4 \mathrm{~m})$ has been found to similarly increase occurrences of hind-leg extension when lying (Boyer et al., 2018). Furthermore, although tiestall cows do still exhibit mid-position and extended posturing of their legs, it is possible that this is performed at the expense of the space and potential comfort of the neighboring cow. Cows in tiestalls were observed with their hind legs in the neighboring stall more than $20 \%$ of the total observed time in the current study. This is comparable to the results of Boyer et al. (2018), who documented hind legs of single-stall cows in the neighboring stall $14.7 \%$ of observed time, but only $1.3 \%$ of the time in cows provided a doublewidth stall. More space provides cows with the ability to fully extend the hind legs without encroaching on the stall space of the neighboring cow. This may have implications for the cow, as disturbances during lying may negatively affect comfort as well as lying time.

A final feature that most often differs between stallbased housing and systems such as our loose pens that used deep-bedded packs is the lying surface. Although not significant, lying time was $1.5 \mathrm{~h} / \mathrm{d}$ higher in the LP cows in the current study, which agrees with previous findings for cows housed in deep-bedded straw yards compared with cubicle housing (Fregonesi and Leaver, 2001). Tucker et al. (2009) found that increased depth and more compressible bedding types positively affected lying time, with differences in lying time up to $1.4 \mathrm{~h} / \mathrm{d}$ between stalls bedded with $3 \mathrm{~kg}$ of wood shavings (compressibility $=1.9 \mathrm{~cm}$ ) versus $7 \mathrm{~kg}$ of straw (compressibility $=14.6 \mathrm{~cm}$ ). However, this difference could also be attributed to normal variations in lying time among individual cows, warranting further investigation. Lying-down ability may, likewise, benefit from a more compressible and comfortable lying surface, as seen by the numerically lower time to lie down among LP cows in our study. This concurs with previous findings by Krohn and Munksgaard (1993), that cows housed in straw yards with pasture access took less time and fewer attempts to lie down than did their tiestall counterparts. Harder lying surfaces can lead to higher incidences of swelling of the carpal joints (Rushen et al., 2007), which may increase the cow's discomfort during the beginning stages of lying, when she drops to her knees, as she is placing a great deal of force on the carpal joints. Deeper bedding or more compressible lying surfaces may absorb some of this force and, thus, increase the ease with which the cow carries out her lying-down behaviors. The compressibility of the LP lying surface was slightly better than that of the stall, suggesting that, although there may have been an increased cushioning effect, compressibility in combination with other aspects of the cow's lying surface may have led to the increased lying time and lying-down ease for LP cows in our study.

\section{CONCLUSIONS}

Housing tiestall dairy cows in a deep-bedded loose pen during the 8-wk dry period proved beneficial to overall lying time, lying and rising ability, and lying posture display. This includes greater ease of movement when transitioning between standing and lying, increased ability to assume different lying postures that may maximize cow comfort, and numeric increases in total lying time. These benefits can be attributed to a combination of fewer obstacles in the cow's environment, increased space for the cow's lying area, and more comfortable lying surface. Many of the results of our study are associated with aspects of the stall itselfa characteristic of both tiestall and freestall housing systems - warranting further research to determine whether cows in freestall systems might also benefit from loose-pen housing during the dry period.

\section{ACKNOWLEDGMENTS}

The authors acknowledge the funding support provided by Novalait (Quebec, QC, Canada), Dairy Farmers of Canada (Ottawa, ON, Canada), and Valacta (Sainte-Anne-de-Bellevue, QC, Canada), as a part of the NSERC Industrial Research Chair in the Sustainable Life of Dairy Cattle. The authors also thank Mitacs for providing student stipend funding through the Accelerate program. We extended our gratitude to Roger Cue (McGill University, Sainte-Anne-de-Bellevue, QC, Canada) for his statistical assistance, as well as to the staff at the McGill Macdonald Campus Dairy Unit for assisting with the animals in the study. Finally, our thanks to research assistant Tania Wolfe (McGill University, Sainte-Anne-de-Bellevue, QC, Canada) and to the numerous interns and students who assisted in data collection over the course of the study.

\section{REFERENCES}

Bouffard, V., A. M. de Passillé, J. Rushen, E. Vasseur, C. G. R. Nash, D. B. Haley, and D. Pellerin. 2017. Effect of following recommendations for tiestall configuration on neck and leg lesions, lameness, cleanliness, and lying time in dairy cows. J. Dairy Sci. 100:29352943 
Boyer, V., E. Edwards, M. F. Guiso, S. Adam, P. Krawczel, A. M. de Passillé, and E. Vasseur. 2018. Would cows benefit from "king-size" beds? J. Dairy Sci. 101(Suppl. 2):220. (Abstr.)

CDIC (Canadian Dairy Information Centre). 2017. Dairy Barn Type in Canada. Accessed Aug. 9, 2018. http://www.dairyinfo.gc.ca/.

Cooper, M. D., D. R. Arney, and C. J. C. Phillips. 2007. Two- or fourhour lying deprivation on the behavior of lactating dairy cows. J. Dairy Sci. 90:1149-1158.

Dairy Farmers of Canada-National Farm Animal Care Council. 2009. Code of Practice for the Care and Handling of Farm AnimalsDairy Cattle. Dairy Farmers of Canada, Ottawa, ON, Canada.

Fregonesi, J. A., and J. D. Leaver. 2001. Behaviour, performance and health indicators of welfare for dairy cows housed in strawyard or cubicle systems. Livest. Prod. Sci. 68:205-216.

Fregonesi, J. A., M. A. G. von Keyserlingk, and D. M. Weary. 2009 Cow preference and usage of free stalls compared with an open pack area. J. Dairy Sci. 92:5497-5502.

Haley, D. B., J. Rushen, and A. M. de Passillé. 2000. Behavioural indicators of cow comfort: activity and resting behaviour of dairy cows in two types of housing. Can. J. Anim. Sci. 80:257-263.

Ito, K., D. M. Weary, and M. A. G. von Keyserlingk. 2009. Lying behavior: Assessing within- and between-herd variation in free-stallhoused dairy cows. J. Dairy Sci. 92:4412-4420.

Krohn, C. C., and L. Munksgaard. 1993. Behavior of dairy cows kept in extensive (loose housing/pasture) or intensive (tie stall) environments II. Lying and lying-down behavior. Appl. Anim. Behav. Sci. 37:1-16.

Medrano-Galarza, C., J. Gibbons, S. Wagner, A. M. de Passillé, and J. Rushen. 2012. Behavioral changes in dairy cows with mastitis. J. Dairy Sci. 95:6994-7002.

Rushen, J., D. Haley, and A. M. de Passillé. 2007. Effects of softer flooring in tie stalls on resting behavior and leg injuries of lactating cows. J. Dairy Sci. 90:3647-3651.
St. John, J., J. Rushen, S. Adam, and E. Vasseur. 2018. The effect of tie-rail placements on neck injuries and lying and rising ability of tiestall-housed dairy cows. J. Dairy Sci. 101(Suppl. 2):362. (Abstr.)

Ternman, E., M. Pastell, S. Agenäs, C. Strasser, C. Winckler, P. P. Nielsen, and L. Hänninen. 2014. Agreement between different sleep states and behaviour indicators in dairy cows. Appl. Anim. Behav. Sci. 160:12-18.

Tucker, C. B., D. M. Weary, M. A. G. von Keyserlingk, and K. A. Beauchemin. 2009. Cow comfort in tie-stalls: Increasing depth of shavings or straw bedding increases lying time. J. Dairy Sci. 92:2684-2690.

USDA. 2014. National Animal Health Monitoring System, Dairy 2014: Dairy Cattle Management Practices in the United States. Accessed Aug. 9, 2018. https://www.aphis.usda.gov/animal_health/ nahms/dairy/.

Vasseur, E. 2017. Animal behavior and well-being symposium: Optimizing outcome measures of welfare in dairy cattle assessment. J. Anim. Sci. 95:1365-1371.

Walker, S. L., R. F. Smith, J. E. Routly, D. N. Jones, M. J. Morris, and H. Dobson. 2008. Lameness, activity time-budgets, and estrus expression in dairy cattle. J. Dairy Sci. 91:4552-4559.

Zambelis, A., M. Gagnon-Barbin, J. St. John, and E. Vasseur. 2018. Development of a rising and lying-down ability index in dairy cattle and its relationship with other welfare outcome measures. Page 110 in Proc. 52nd Congr. Int. Soc. Appl. Ethol.: Ethology for Health and Welfare, Univ. Prince Edward Island, Charlottesville, Canada. Wageningen Academic Publishers, Wageningen, the Netherlands 